\title{
Feeding behaviour of fifteen species of hermit crabs (Crustacea: Decapoda: Anomura) from the Otago region, southeastern New Zealand
}

\author{
PATRICK J. SCHEMBRI $\dagger$ \\ University of Otago, Portobello Marine Laboratory, \\ P.O. Box 8, Portobello, New Zealand
}

\section{Introduction}

Hermit crabs are common and conspicuous members of intertidal and subtidal habitats. Although there exists an extensive literature on their behaviour, in the main this deals with shell related behaviour such as shell selection and shell fighting, and with behaviour patterns associated with the various symbiotic relationships of which hermit crabs form part (see the extensive bibliography in the recent review of hermit crab behavioural ecology by Hazlett 1981). Other aspects of their behaviour have received much less attention.

A number of studies on hermit crab feeding behaviour have been made. However, relative to the number of living species (estimated at $\simeq 700$, Alcock 1905, Gordan 1956) very few have been investigated. Moreover, those species which have been studied to date all belong to genera of only two out of six families of marine hermit crabs (the Diogenidae and the Paguridae), and are intertidal or shallow water species. The feeding behaviour of hermit crabs belonging to less well known families or genera or from less accessible habitats has not been studied. Nonetheless the available data are sufficient to show that these animals have a wide range of feeding mechanisms including deposit-feeding, suspension-feeding, predation and scavenging. Often a species is able to feed in different ways depending on what food is available at the time (Kunze and Anderson 1979, Schembri, 1982). Given such complexity of behaviour, a larger cross-section of species from a wider taxonomic range and from more diverse habitats needs to be investigated before evolutionary trends and adaptive radiation within the group can be studied.

Sixteen species of hermit crabs belonging to four families are known to occur in the Otago region (table l; the late E. J. Batham unpublished data, C. L. McLay personal communication) in habitats ranging from rocky intertidal through relatively coarse sediments of various sorts on the continental shelf to finer sediments on the continental shelf edge and slope. This rich fauna presented an ideal opportunity to study feeding in hermit crabs from a variety of taxonomic groupings and habitat types. Here the feeding behaviour and feeding mechanisms of 15 species of Otago hermit crabs are described and discussed in relation to their morphology, habitat and previous work on feeding in hermit crabs.

\section{Material and methods}

Intertidal hermit crabs were collected by hand from the shore at Warrington $\left(45^{\circ} 42.8^{\prime} \mathrm{S}, 170^{\circ} 35.8^{\prime} \mathrm{E}\right)$. Subtidal hermit crabs were collected by dredging off the

\footnotetext{
$\dagger$ Present address: 72 Brared Street, B'Kara, Malta: 
Table 1. Classified list of the hermit crabs of the Otago region with the names used in two previous publications by Probert et al. (1979) and Rainer - (1981).

\begin{tabular}{|c|c|c|c|}
\hline & & Name used by Probert et al. (1979) & Name used by Rainer (1981) \\
\hline Superfamily & COENOBITOIDEA & & \\
\hline \multirow[t]{2}{*}{ Family } & Pylochelidae & & \\
\hline & Mixtopagurus sp. nov. & Mixtopagurùs spinosus (Henderson) & - \\
\hline \multirow{3}{*}{ Family } & Diogenidae & & \\
\hline & Paguristes barbatus (Heller, 1862) & Payuristes subpilosus (Henderson) & - \\
\hline & Paguristes pilosus (H. Milne-Edwards, 1837) & & - \\
\hline \multirow{5}{*}{$\begin{array}{r}\text { Superfamily } \\
\text { Family }\end{array}$} & PAGUROIDEA & & \\
\hline & Paguridae & & \\
\hline & Pagurus sp. nov. A $\dagger$ & Porgurus sp. 'pink and white' & [?] Pagurus sp. nov. 1 \\
\hline & Payurus sp. nov. B & -1 & [?] Pagurus sp. nov. (aff, traversi) \\
\hline & Pagurus traversi (Filhol, 1885) & - & - \\
\hline \multirow[t]{9}{*}{ - } & Pagurus novaezelandiae (Dana, 1852) & - & - \\
\hline & 'Pagurus' rubricatus (Henderson, 1888) & Pagurus rubricatus (Henderson) & - \\
\hline & Pagurus' spinulimanus (Miers, 1876) & Pagurus spinulimanus (Miers) & Pagurus spimulimanus (Miers) \\
\hline & Australeremus cooki (Filhol, 1883) & Pylopagurus cooki (Filhol) & Pagurus cooki \\
\hline & Pylopagurus stewarti (Filhol, 1883) & Pylopagurus stewarti (Filhol) & - \\
\hline & Pylopagurus sp. nov. & $\begin{array}{l}\text { Pylopagurus sp. 'pale vermilion, } \\
\text { mottled/barred' }\end{array}$ & Pagurus sp. nov. (aff. cooki) \\
\hline & Lophopagurus 'thompsoni' (Filhol, 1885) & Pylopagurus sp. 'mauve antenna 1' & Pagurus sp. nov. (aff. thomsoni) \\
\hline & Lophopagurus sp. nov. & Pylopagurus crenatus (Borradaile) & - \\
\hline & Pagurid 'smooth apricot' [gen. nov., sp. nor.] & Pagurid 'smooth apricot' & - \\
\hline \multirow[t]{2}{*}{ Family } & Parapaguridae & & \\
\hline & Parapayurus dimomphus (Studer, 1883) & Parapagurus dimorphus (Studer) & - \\
\hline
\end{tabular}

$\dagger$ This species was not found in sufficient numbers to study feeding behaviour and is not mentioned in the text. 
Otago Peninsula $\left(45^{\circ} 40.0^{\prime}-46^{\circ} 00.0^{\prime} \mathrm{S}, 170^{\circ} 40.0^{\prime}-171^{\circ} 08.0^{\prime} \mathrm{E}\right)$ using either a $0.56 \mathrm{~m}$ wide Agassiz trawl with traps to collect sediment fitted to the trawl runners (McDougall 1973) or a $2 \mathrm{~m}$ wide beam trawl. In the laboratory the crabs were kept on their natural substratum in holding tanks supplied with circulating seawater. The crabs foraged on the substratum and were not given any additional food but the sediment was changed at irregular intervals.

Observations on feeding behaviour were made in a darkroom using a red $15 \mathrm{~W}$ lamp as the only source of light. The observation aquaria consisted of 'Perspex' tanks $(14 \times 14 \times 10 \mathrm{~cm})$ filled to a depth of $2 \mathrm{~cm}$ with sediment and supplied with a slow flow of seawater. Animals were acclimatized overnight to the aquarium before observations were started. Observations were made on crabs on (i) their natural substratum, (ii) gravel (2-6 mm fraction), (iii) sand (250-500 $\mu \mathrm{m}$ fraction) and (iv) mud $(<90 \mu \mathrm{m}$ fraction). The last three substrata were used to study how feeding behaviour was affected by sediment type since the natural substrata of the crabs were usually very heterogeneous (Andrews 1973, Probert et al. 1979).

Individuals were given a variety of different sized bivalves, gastropods and amphipods to test whether they preyed upon these or not and were also offered carrion (pieces of crushed molluses or polychaetes). Detailed observations on each species were made in the laboratory on individuals housed in a 'Perspex' aquarium $(19 \times 7.5 \times 18 \mathrm{~cm})$ úsing a travelling stereomicroscope. Casual observations were made on crabs in the holding tanks and, in the case of intertidal species, on the shore. At least 10 individuals of each species and sometimes 30 or more were observed and the following descriptions of feeding behaviour are pieced together from these various observations.

Morphology was studied by dissection and by optical and scanning electron microscopy as already described (Schembri 1982). Water currents were traced using suspensions of milk or fine mud particles in seawater.

\section{Species studied, distribution, and type of shelter occupied}

The taxonomy of New Zealand hermit crabs is currently under revision by J. Forest and M. de Saint Laurent of the Muséum national d'Histoire naturelle, Paris (C. L. McLay personal communication). Of the 16 species which occur in the Otago region, six are as yet undescribed (C. L. McLay personal communication). Two pagurids, 'Pagurus' rubricatus and 'Pagurus' spinulimanus will be transferred to a new genus in Forest and de Saint Laurent's revision (Hyden and Forest 1980) and for this reason the generic name Pagurus is placed in quotes when used for these species. The 'pylopagurid-like' hermit crabs of the world are currently being reviewed by MeLaughlin (1981 and papers in preparation) who has split the genus Pylopagurus into several new genera. The five species of this group which occur in the study area have been assigned to these new genera using the key given in McLaughlin (1981). The specific name thompsoni for Lophopagurus 'thompsoni' is placed in quotes to indicate that it is only used provisionally pending revision since this name is apparently preoccupied (P. A. McLaughlin personal communication, C. L. McLay personal communication).

Two previous works on the benthic fauna of the Otago region (Probert et al. 1979, Rainer 1981) have included the hermit crabs. Because of the uncertainty in nomenclature and to facilitate comparison between this study and those of Probert et al. (1979) and Rainer (1981), the equivalent names used by these authors are given in table 1 . The identity of these authors' species was ascertained by examination of 
Table 2. Average size, distribution off the Otago Peninsula and main type of shelter occupied by the Otago hermit crab species.

Key: (i) Distribution (in order of increasing depth): It, intertidal; Is, inner shelf: MS. midshelf; Os, outer shelf; UC, upper canyon: DC, deep eanyon. (ii) Size: large, 16-9 mm carapace length; medium, 9-6 mm e.l.; small, $6-3 \mathrm{~mm}$ c.l.; very small $<3 \mathrm{~mm}$ c.l. Nee text for further details.

\begin{tabular}{|c|c|c|c|}
\hline Species & Size & Distribution & Main shelter type \\
\hline Mixtopagurus sp. nov. & small & $\mathrm{UC}-\mathrm{DC}$ & $\begin{array}{l}\text { polychaete tubes, } \\
\text { gastropod shells }\end{array}$ \\
\hline Paguristes barbatus & medium-large & MS-UC & gastropod shells \\
\hline Paguristes pilosus & large & IS-MS & gastropod shells \\
\hline Pagurus sp. nov. A & small & IS & gastropod shells \\
\hline Pagurus sp. nov. B. & very small & IS-MS & $\begin{array}{l}\text { gastropod shells, } \\
\text { bryozoan tubes }\end{array}$ \\
\hline Pagnurus traversi & small & It & gastropod shells \\
\hline Pagurus novaezelandiae & medium-large & It-IS & gastropod shells \\
\hline 'Pagurus' rubricatus & large & MS-OS & gastropod shells \\
\hline 'Pagurus' spinulimanus & large & MS-OS & gastropod shells \\
\hline Australeremus cooki & smail & MS-OS & $\begin{array}{l}\text { gastropod shells, } \\
\text { bryozoan tubes }\end{array}$ \\
\hline Pylopagurus stewarti & small & MS-UC & $\begin{array}{l}\text { bryozoan and } \\
\text { polychaete tubes }\end{array}$ \\
\hline Pylopagurus sp. nov. & small & MS-OS & $\begin{array}{l}\text { bryozoan and } \\
\text { polychaete tubes, } \\
\text { gastropod shells }\end{array}$ \\
\hline Lophopagurus 'thompsoni' & medium & IS-OS & gastropod shells \\
\hline Lophopagurus sp. nov. & medium & $\mathrm{CC}-\mathrm{DC}$ & gastropod shells \\
\hline Pagurid 'smooth apricot' & medium-large & $\mathrm{UC}-\mathrm{DC}$ & gastropod shells \\
\hline Parapagurus dimorphus & large & $U C-D C$ & gastropod shells \\
\hline
\end{tabular}

specimen's, photographs and the personal notes of the late E. J. Batham deposited at the Portobello Marine Laboratory, New Zealand. To avoid possible confusion, specimens of each species referred to in the present work have also been deposited at the Portobello Marine Laboratory.

The distribution of some species of hermit crabs off the Otago coast in relation to sediment type has been studied by Probert et al. (1979). Additional information on their distribution in Otago Harbour and Blueskin Bay is provided by Rainer (1981). Table 2 gives an indication of the bathymetric range of each of the 16 species of Otago hermit crabs based on surveys carried out during the present study.

The inner shelf region extends from low tide mark to $\simeq 40 \mathrm{~m}$ depth. The bottom in this region consists of sand and muddy sand with little organic skeletal debris. The mid-shelf region extends from $\simeq 40 \mathrm{~m}$ to $\simeq 120 \mathrm{~m}$ while the outer shelf region extends from this depth to the edge of the continental shelf $(\simeq 200 \mathrm{~m})$. The sediments in these regions consist of gravels, sandy gravels and gravelly sands all rich in organic skeletal debris. The upper canyon region extends from the continental shelf edge to $\simeq 400 \mathrm{~m}$ and the bottom here consists of gravelly sand with varying amounts of skeletal material. Below this depth lies the deep canyon region where the sediment becomes progressively more muddy with increasing depth. The terminology for these bathymetric regions is the same as that used by Probert et al. (1979). This work and that of Andrews (1973) give detailed descriptions of bottom sediments, bathymetry and faunal assemblages. 
Table 2 also gives an indication of the average size of the species considered and the main types of shelter occupied by them. As will be discussed below, the type of shelter may have a profound effect on feeding behaviour. Apart from empty gastropod shells some crabs occupy empty calcareous polychaete tubes which have become detached from their original substratum (attached tubes are rarely occupied) and 'bryozoan tubes'. The latter are a result of a mutualistic association between certain species of bryozoans and hermit crabs in which a newly metamorphosed hermit crab occupies a small gastropod shell which is subsequently colonized by a bryozoan ancestrula. The colony grows to cover the entire surface of the shell and continues growing round the aperture in the form of a spiral tube. As the hermit crab grows larger the tube lengthens until the crab grows too large for the original shell and lives exclusively in the tube (see also Morton and Miller 1968 pp. 574-577, Cook 1964, 1968, Taylor and Cook 1981). The crabs probably occupy the same tube throughout their lives.

A small percentage of individuals of species other than those listed as occupying bryozoan tubes (table 2) may also live in these shelters while a small number of individuals of species which are normally bryozoan associates may live in ordinary gastropod shells or in polychaete tubes. A detailed analysis of distribution patterns, occupancy of different shelter types and ecology of the Otago hermit crab species will be given in a separate paper.

\section{Feeding behaviour}

Based on an earlier scheme proposed by Yonge (1956), Newell (1979) has classified the feeding activities of marine invertebrates into browsing, predation, scavenging, suspension-feeding and deposit-feeding mechanisms. Each of these is used by one or more of the species considered here and most species use more than one mechanism. Deposit-feeding is usually defined as the ingestion of sediment particles and the assimilation of microscopic organisms coating the particles (e.g. Hughes 1980 , p. 424 ). Here deposit-feeding is used in its broadest sense to include feeding on organic detritus obtained from sediment particles of any size up to and including small pebbles as well as feeding on detritus which collects in irregularities in the surface of larger objects.

In the following descriptions, the terms 'major' and 'minor' cheliped (or pincer) refer to the right and left appendage respectively except for Paguristes pilosus where the major chela is the left. In Mixtopagurus sp. nov: and Paguristes barbatus the chelipeds are equal. Setae are named according to the nomenclatural scheme of Factor (1978).

\section{Mixtopagurus sp. nov.}

Aspects of the behaviour of this species have been described by Batham (1970), however this author did not observe feeding. Mixtopagurus sp. nov. is primarily a deposit-feeder but feeds also by browsing, scavenging and suspension-feeding.

On their natural substratum the crabs fed by scraping material from the surface of gravel granules, pebbles, shells or any other solid surface using the tips of the chelae. The tip of the chela is applied to the surface and the pincer opened and closed a few times. As the dactyl is flexed, its tip scrapes material from the surface (fig. 1). When enough material has accumulated in the concave ventral surface of the pincer, this is brought to lie underneath the 3rd maxillipeds which then transfer the aceumulated debris to the other mouthparts. When placed on sand or mud the crabs 

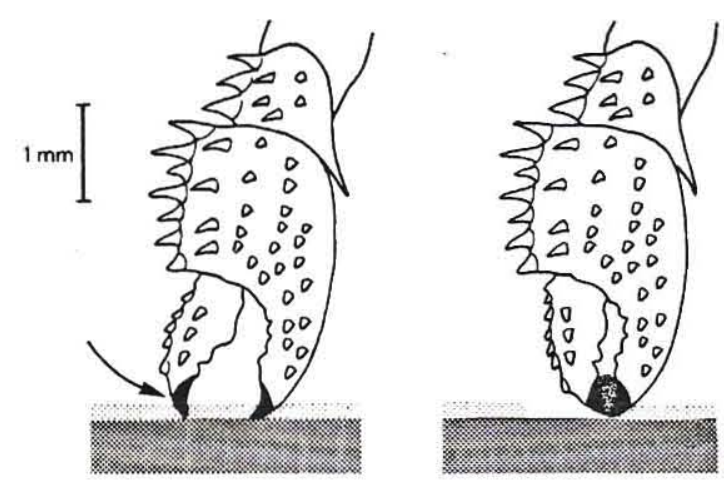

FIG. 1. Mixtopagurus sp. nov. scraping detritus off a surface using the tip of the pincer: drawn from life; for clarity the setae on the pincer are not shown.
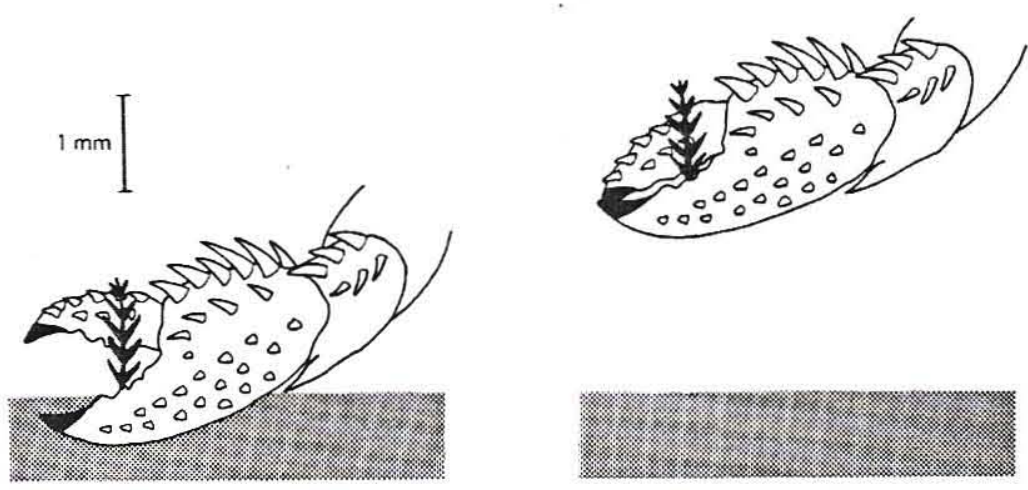

FIG. 2. Mixtopagurus sp. nov. using the teeth of the cutting edge of the pincer to pluck off a hydroid colony from the substratum: drawn from life; for clarity the setae on the pincer are not shown.

fed on the sediment which they transferred to the mouthparts using the concave ventral surface of the pincers as scoops, the two chelae working alternately. The dactyls of the walking legs were also sometimes used to transfer sediment to the mouthparts. When pebbles were introduced, the crabs fed preferentially on these by scraping and browsing.

Soft epilithic organisms attacherl to solicl surfaces were gripped by the tips of the pincers and plucked off. Harder organisms such as hydroid and bryozoan colonies were ripped off using the teeth on the cutting edges of the pincers (fig. 2). These teeth were also used to crunch up hard material before it was transferred to the mouthparts. The erabs readily accepted and fed upon pieces of mollusc flesh.

As the crabs foraged on the substratum, the long setae of the chelipeds, walking legs and cephalothorax trapped particles from the sediment and from suspension. These particles were eventually brushed off and ingested. The exopodites of the 2 nd and 3rd maxillipeds generated water currents similar to those described for 'Pagurus' rubricatus (Schembri 1982, see also Batham 1970) and as in this species particles carried by these currents were trapped by the setose mouthparts. Apart from the antennules and the mouthparts, however, the other appendages were only groomed at irregular intervals when experimentally covered with fine mud particles suggesting that Mixtopagurus sp. nov, obtains particles from suspension fortuitously. 


\section{Paguristes barbatus}

$P$. barbatus fed in much the same way as Mixtopagurus sp. nov. by scraping detritus from the surface of objects using the tips of the pincers of both the right and left chelipeds. The spines on the tips of the dactyls of the walking legs were used to dislodge material from surfaces. The crabs overturned gravel granules and small pebbles of suitable size and scraped material off their under-surface and fed on the sediment underneath which they scooped up with the chelae (ef. Mixtopagurus sp. nov.). When tested, the crabs fed on sand or mud but as in Mixtopagurus sp. nov. they preferred to feed by scraping the surface of pebbles when these were made available.

The crabs browsed on epilithic and epizoic organisms adhering to pebbles, shells and to animals such as sponges, ascidians and bryozoans. Material was gripped by the teeth of the cutting edge of the pincers and plucked off. Unlike Mixtopagurus sp. nov., $P$. barbatus were not observed to break pieces off bryozoan colonies nor break up hard material with the pincers. Pieces of molluse flesh were readily accepted and eaten.

The pereiopods and cephalothorax of $P$. barbatus are densely covered with short matted plumose setae, but no evidence for suspension-feeding was found. Unlike the simple setae of Mixtopagurus sp. nov. these do not trap sediment.

\section{Paguristes pilosus}

P. pilosus is a suspension and deposit-feeder. This species is closely related to P. setosus of northern New Zealand the feeding behaviour of which has been described in detail by Greenwood (1972) as Stratiotes setosus.

As in $P$. setosus, $P$. pilosus filtered out particles from suspension using the antennae, each of which carries a double row of long plumose setae arranged at an internal angle of $\simeq 100^{\circ}$ to each other. The mechanism of suspension feeding corresponds in every detail to that of $P$. setosus except that rather than tracing a broadly circular path, the antennal peduncle traced a figure of eight with very unequal loops (fig. 3). The smaller loop lay in a frontal plane while the larger loop lay

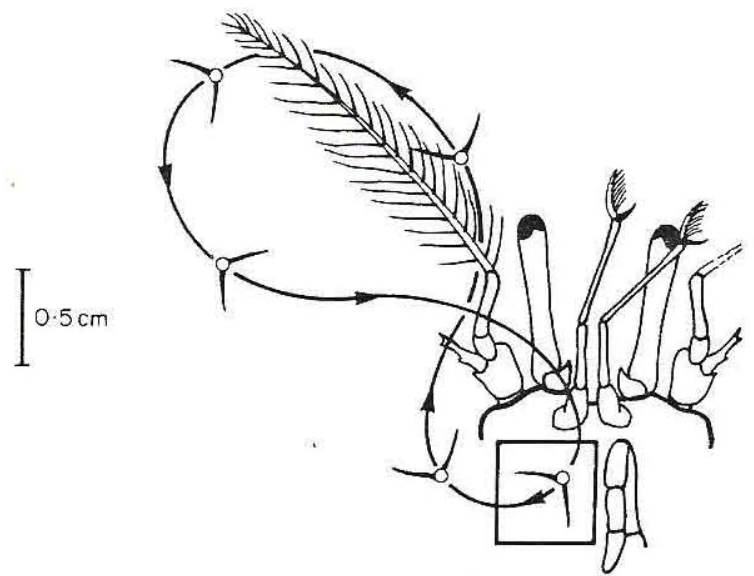

FIG. 3. Paguristes pilosus suspension-feeding showing the path traced by the antenna and the orientation of the antennal flagellum setae relative to the direction of movement. The boxed area indicates the region where the sweep of the antenna is interrupted for the 3rd maxillipeds to brush off particles trapped by the antennal flagellum setae; drawn from life. 
in a plane at right angles to this (fig. 3). At its lowest point of travel in the smaller loop, the flagellum was rotated as described by Greenwood (1972) such that the setal net always faced the direction of movement. Periodically the antennae were cleaned by the endopodites of the 3rd maxillipeds which gripped the flagellum proximally from either side and brushed distally (cf. grooming in 'Pagurus' rubricatus, Schembri 1982). As in $P$. setosus the two antennae beat synchronously, alternately or completely independently of each other.

The crabs fed on sediment which they scooped up in the pincer of the minor chela and sometimes in that of the major chela, or with the walking legs. Only fine sediment was taken, gravel granules were not picked up.

When pieces of mollusc flesh were introduced into the aquaria containing the crabs, they responded by filtering water and/or feeding on the sediment at much higher rates than previously, but did not orientate towards the food. When pieces of food were placed very close to a crab, the animal siezed them and fed readily on them using the major chela to manipulate the food and the minor chela to tear pieces out and convey them to the mouthparts.

Pagurus sp. nov. B

Pagurus sp. nov. B is a deposit-feeder and general scavenger although a certain amount of food is obtained by suspension-feeding.

Detritus was collected in a number of ways. Sediment was scooped up by the minor chela. With the dactyl extended, the pincer was thrust into the sediment; the dactyl was then flexed and the whole cheliped drawn towards the body collecting sediment in the concave ventral surface of the pincer which is surrounded by tufts of setae and makes an efficient scoop. The major chela and the walking legs were also occasionally used to collect sediment. Sediment was then transferred to the mouthparts where it was sorted. Larger particles were picked up individually, cradled between the endopodites of the 2 nd and $3 \mathrm{rd}$ maxillipeds and scrubbed clean of detritus by the inner mouthparts in a manner similar to that in 'Pagurus' rubricatus (Schembri 1982). The pereiopods are densely covered with long simple setae which trapped particles from the sediment as the crabs walked about on the substratum. These setae were preened frequently by the chelipeds; each pincer preened the setae on the dorsal surface of the opposite cheliped and the pincer of the minor cheliped was used to preen the setae of the walking legs. Particles collected in

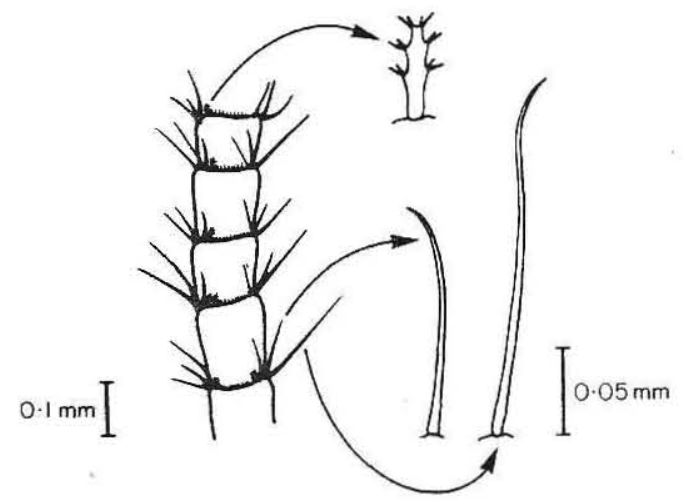

Fig. 4. Pagurus sp. nov. B; antennal flagellum showing arrangement and type of setae; drawn from a scanning electron micrograph. 


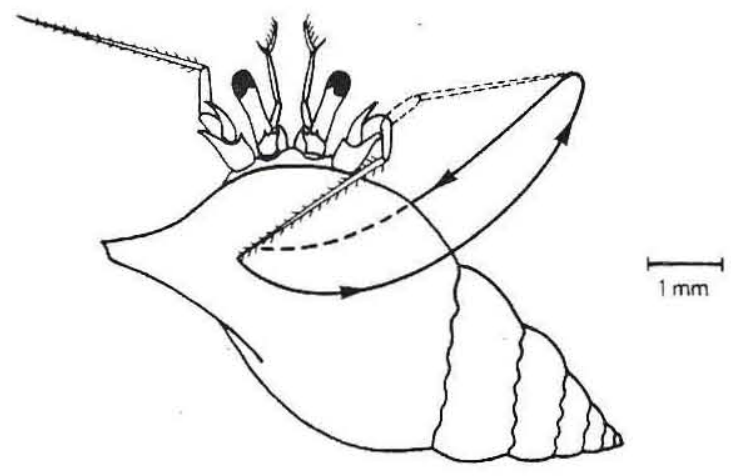

Fig.5. Pagurus sp. nov. B: scraping detritus from the shell with the antennal flagellum. The path of movement of the flagellum is shown by the arrows: the broken line indicates that region where the flagellum is in contact with the shell surface; drawn from life.

this way were then ingested. The crabs obtained a substantial amount of detritus simply by regularly cleaning the appendages. The setae of the chelipeds also trapped particles suspended in the water currents generated by beating the exopodites of the 2nd and 3rd maxillipeds (ef. ' $P$ '. rubricatus, Schembri 1982).

Detritus was also obtained by using the tip of the pincer of the minor chela, and occasionally that of the major chela, to scrape surfaces as in Mixtopagurus sp. nov. Detritus was obtained from the shell occupied by the crab by a peculiar mechanism involving the antennae. The flagella of these are sparsely covered with simple setae of various lengths and with very short plumodenticulate setae (fig. 4). The flagella were flexed backwards until they touched the shell and were then swept obliquely across its surface and brought forwards again; material adhering to the flagellum setae was then brushed off by the 3rd maxillipeds (fig. 5). Carrion was taken readily by the crabs as was other organic debris lying on the bottom of the aquaria.

\section{Pagurus traversi}

$P$. traversi is a browser and deposit-feeder and also an opportunistic scavenger and predator.

The crabs fed on intertidal algae which they either sliced off using the major pincer or plucked off using either pincer. The algae were shredded by the chelae before ingestion. Detritus was picked up from amongst or beneath algal tufts by the minor chela. The minor chela and sometimes also the major chela and walking legs were used to scoop up sediment. Gravel particles were picked up individually and manipulated by the major chela while the minor chela scraped detritus from their surface (cf. scraping in Mixtopagurus sp. nov.). No attempts at 'gravel-scrubbing' (see Pagurus sp. nov. B) were observed. The major pincer was used to crush gravel particles and other hard material into smaller sized fragments. Particles collected casually by the long simple setae covering the pereiopods were brushed off and ingested when the crabs preened themselves (cf. Pagurus sp. nov. B).

Small gastropods, bivalves and other invertebrates disturbed by the crabs when they foraged amongst algae were captured, crushed by the teeth of the cutting edge of the major pincer and eaten. The crabs also fed readily on carrion. 


\section{Pagurus novaezelandiae}

P. novaezelandiae is a deposit-feeder and a scavenger. Feeding in this species has already been studied by Greenwood (1972) and the observations made during the present study support fully this author's descriptions.

The crabs scooped up sediment with the minor chela and sometimes with the major chela and the walking legs. The walking legs were used to sweep in sediment lying laterally to the crab and push it underneath the body below the $3 \mathrm{rd}$ maxillipeds whose endopodites were then applied directly to the sediment and brushed particles up to the other mouthparts. Gravel granules were picked up and scrubbed as described for Pagurus sp. nov. B and ' $P$ '. rubricatus (Schembri, 1982). The crabs fed on carrion and orientated towards and fed readily on recently dead or moribund organisms.

\section{'Pagurus' rubricatus and 'Pagurus' spinulimanus}

Both species are predators, deposit-feeders, scavengers and, to a small extent, suspension-feeders. The feeding mechanisms of ' $P$ '. rubricatus have already been described (Schembri 1982) and ' $P$ '. spinulimanus fed in exactly the same ways. The only difference noted between these two species was that ' $P$ '. spinulimanus did not excavate trenches in the sediment but rather foraged on the debris lying on the surface. This species was also less active than ' $P$ '. rubricatus.

\section{Australeremus cooki}

A. cooki is a deposit and a suspension-feeder and to a lesser degree a scavenger.

Sediment was picked up mainly by the minor chela and occasionally also by the major chela and the walking legs while the chelae were used to scrape detritus from surfaces as described for Mixtopagurus sp. nov. Material was picked up from the sediment and from surfaces using the tips of the pincers as forceps, particularly that of the minor chela.

The crabs filtered particles out of suspension using the setae on the antennae. These appendages are covered with plumose setae and longer specialized plumodenticulate setae whose proximal $1 / 3-1 / 2$ carries two rows of long filamentous setules

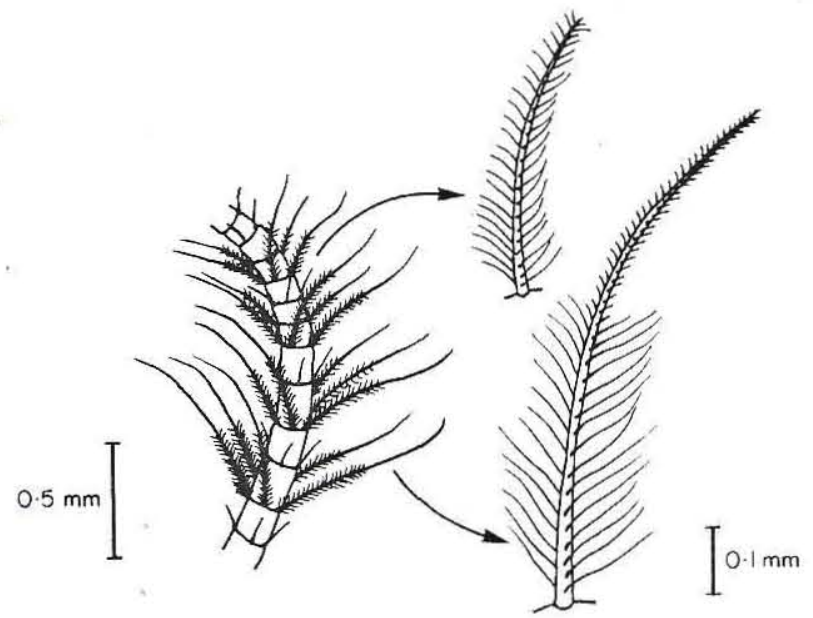

Fig. 6 Australeremus cooki: antennal flagellum showing arrangement and type of setae; drawn from a scanning electron micrograph. 


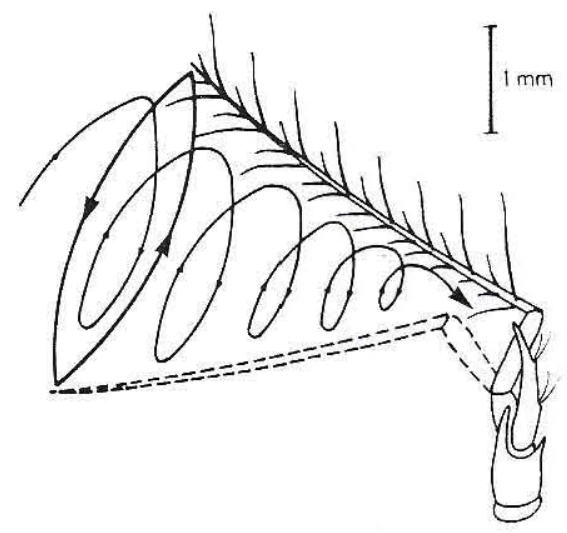

FIG. 7. Australeremus cooki: movement of the antennal flagellum (thick line) and water currents generated (narrow spiral line) during suspension-feeding; drawn from life.

arranged at an internal angle of $\simeq 120^{\circ}$ to each other. Distally these setules are replaced by much shorter denticulations (fig. 6). During suspension-feeding the antennal flagella were synchronously or alternately twirled round such that their tips described a more or less circular path (fig. 7). This caused a current of water to spiral in from the tip of the flagellum towards its base (fig. 7). Particles carried in this water current became entangled in the filamentous setules of the antennal setae and were periodically brushed off by the endopodites of the $3 \mathrm{rd}$ maxillipeds and ingested (cf. Paguristes pilosus). The antennules also carry two rows of these specialized plumodenticulate setae on their peduncle segments, arranged at an internal angle of $\simeq 40^{\circ}$ and pointing anteriorly. During the normal flicking movements of the antennules (described for Pagurus alaskensis by Snow 1973) these setae also strained particles out of suspension.

Although individuals of $A$. cooki were observed feeding on carrion, when offered pieces of molluse flesh, the crabs quite often discarded them after feeding for a short time indicating that they are not particularly active scavengers.

Pylopagurus stewarti and Pylopagurus sp. nov.

Both species are primarily suspension and deposit-feeders but also scavenge. In addition Pylopagurus sp. nov. is a browser and a predator.

Particles were filtered out from suspension using the antennae, antennules and the pereiopods. The antennae carry setae similar to those of Australeremus cooki except that the filamentous setules are much shorter in the Pylopagurus spp. The pereiopods carry long simple and plumodenticulate setae. When suspension feeding the crabs extended the anterior part of their body out of their shelter and spread the antennae and pereiopods such that these appendages formed a fan round the body (fig. 8). In still water the antennae were twirled round as in Australeremus cooki while the pereiopods were gently waved to and fro (fig. 8). Particles trapped by the setae on these appendages were brushed off by the 3rd maxillipeds and ingested. In flowing water the crabs orientated their bodies such that they faced into the current and did not move their appendages, except for the antennules which continued flicking. In both species these appendages carry plumodenticulate setae on their peduncles arranged as in Australeremus cooki and are probably also used for suspensionfeeding. 


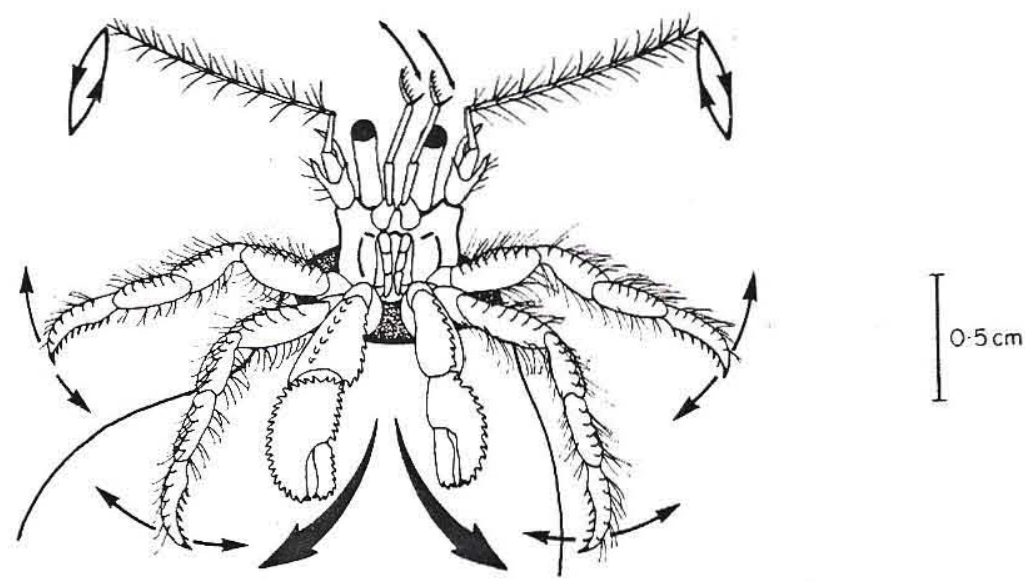

FIG. 8. Pylopagurus sp. nov.: posture of the crab when suspension-feeding in still water; the paths traced by the antennae, antennules, chelipeds and walking legs as they are swept through the water are indicated by the arrows: drawn from life.

When placed on sand or mud both species scooped up particles with the chelipeds as in Pagurus sp. nov. B. Coarse sand grains were picked up individually. The crabs had great difficulty in moving over the soft substrata and climbed onto any available pebble or shell or onto each other. On their natural substratum both species fed on detritus obtained by scraping pebbles and other objects with the tips of the pincers as in Mixtopagurus sp. nov., or with the spines on the tips of the dactyls of the walking legs. The pincer of the minor chela was used as a pair of forceps to pick material up from surfaces (cf. A ustraleremus cooki). Both species fed readily on all sorts of organic debris and on carrion.

Pylopagurus sp. nov. but not $P$. stewarti was observed to graze on bryozoan zooids which the crabs exposed by chipping away at the colony with the pincers of the major chela. No feeding on bryozoan colonies making up the 'bryozoan tubes' inhabited by this species was observed, however. One individual was observed to capture a small rissoid gastropod, crack its shell open with the teeth of the eutting edge of the major chela and eat it.

\section{Lophopagurus 'thompsoni' and Lophopagurus sp. nov.}

Both species are deposit-feeders and active scavengers.

Sediment was scooped up to the mouthparts for sorting by the pincers of the chelae as described for Payurus sp. nov. B. Both chelae were used, usually working in alternation, as well as the dactyls of the walking legs, the latter especially when feeding on fine cohesive sediment. When feeding on sand or mud, $L$. 'thompsoni" but not $L$. sp. nov. exposed the subsurface sediment by shovelling it away with alternate strokes of the chelipeds. The manus of the chela was laid dorsal surface down on the substratum and then extended away from the crab pushing sediment in front of it (fig. 9). This process was repeated until a small patch of subsurface sediment was exposed. On gravel both species picked up small granules to expose the underlying sediment. Small pebbles too large to be picked up were pushed aside. Neither species was observed to scrub gravel granules nor scrape detritus from surfaces. The pincers of the minor chela however were often used as forceps to pick material up from irregularities on pebbles, shells and other surfaces (cf. Australeremus cooki). 

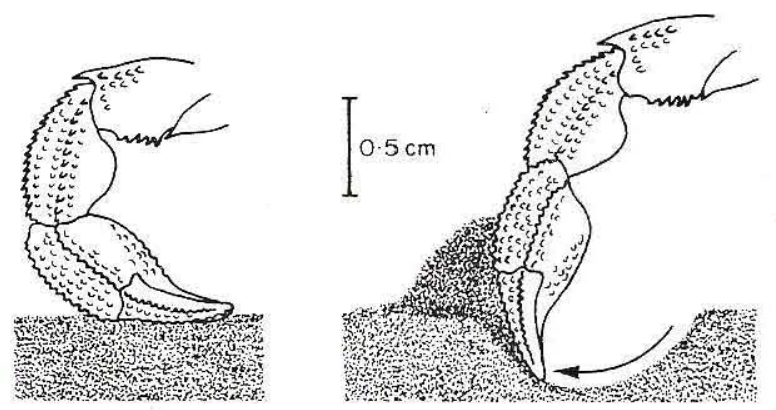

FIx. 9. Lophopagurus 'thompsoni" exposing subsurface sediment using the major chela prior to feeding on it; drawn from life.

Both species investigated and ingested any organic debris they came across while foraging and orientated towards and fed upon carrion and moribund organisms. Yacromaterial was manipulated by the major chela while the minor chela was used to tear pieces off and convey them to the mouthparts.

\section{Pagurid 'smooth apricot' [gen. nov., sp. nov]}

This species is a deposit-feeder and probably a predator and, to some extent, a scavenger and suspension-feeder.

Sediment was scooped up by the pincer of the minor chela as already described for Pagurus sp. nov. B. The major chela and the walking legs were also occasionally used for this activity. Gravel granules were picked up by the minor chela and scrubbed by the mouthparts as in 'Pagurus' rubricatus (Schembri 1982) although in the present species this mechanism is much less organized. The pincer of the minor chela was used as a pair of forceps to pick detritus up from between gravel particles.

The crabs probed the sediment with the pincer of the minor chela, presumably looking for prey since pieces of gravel or shell fragments buried in the sediment were dug up and examined. The major chela which is much larger than the minor chela was often used to crush any object dug up to smaller pieces. No actual capture of prey was observed, however. When given small live gastropods, the crabs attempted to crack them open by crushing the shell in the major pincer and succeeded in doing so if the snail was not too large. The crabs readily accepted and fed upon pieces of polychaete worms.

This species has very long antennae which bear long setae densely covered with short filamentous setules. The crabs were occasionally observed to twirl the antennal flagella round as described for Australeremus cooki and then brush them clean with the 3rd maxillipeds. Although this suggests that the crabs may filter particles from suspension, the relative infrequency of this behaviour indicates that this is probably not an important feeding mechanism.

\section{Parapagurus dimorphus}

$P$. dimorphus is a deposit-feeder and probably also a predator and scavenger.

On their natural substratum of muddy sand, the crabs dug pits up to $1.5 \mathrm{~cm}$ deep in the sediment using the large flattened pincer of the major chela in much the same way that 'Pagurus' rubricatus uses its minor pincer to dig (Schembri 1982). In between the digging strokes of the major chela, the minor chela scooped sediment up to the mouthparts. Occasionally the major chela was paddled to and fro in the sediment at the bottom of the pit, presumably to stir up fine organic particles. 
The pincer of the minor chela probed the sediment and picked out material which was then transferred to the mouthparts (cf. Pagurid 'smooth apricot'). Gravel granules, shell fragments and other similar objects were scrubbed by the inner mouthparts (cf. 'Payurus' rubricatus, Sichembri 1982). When offered small bivalves and gastropods the crabs attempted to break the shells open with the pincer of the major chela but were only successful if the prey organism was very small. Probably $P$. dimorphus preys upon soft-bodied invertebrates which the crabs disturb while digging and probing in the sediment. The crabs readily accepted and fed upon carrion.

Both chelipeds of $P$. dimorphus are covered with matted plumose setae on their dorsal surface but these did not appear to trap sediment particles and no evidence of suspension feeding was found.

\section{Discussion}

Kunze and Anderson (1979) have reviewed most of the available information on feeding in hermit erabs and have concluded that 'the basic adaptation in this group is to a generalized omnivorous mode of feeding on benthic particulate, detrital and moderately macroscopic material'. I have reached a similar conclusion from my observations on feeding in the Otago hermit crabs.

Irrespective of taxonomic position or habitat, all 15 species considered here are primarily deposit-feeders. The basic feeding mechanism is to use the chelipeds, and occasionally the walking legs, to scoop sediment up to the mouth region and there to sift out the finer detrital particles and reject the coarser sediment grains. This behaviour, which I have termed 'scooping', is shown by all the Otago species (table 3) and by the majority of other species studied (e.g. Clibanarius vittatus, Caine 1975; C. taeniatus, ('. virescens, Kunze and Anderson 1979; Pagurus bernhardus, Jackson 1913, Orton 1927, Samuelson 1970; P. longicarpus, Thompson 1904, Roberts 1968; P. cuanensis, P. prideauxi and Anapagurus chiroacanthus, Samuelson 1970). Primitively, most hermit crabs probably fed in this way. Some species have evolved variations of this technique which enable them to deal with coarser particles. Thus, relatively large particles are picked up individually and scrubbed clean of their surface detrital film by the mouthparts (termed 'scrubbing', see also Schembri 1982), while detrital material adhering to surfaces is scraped off with the tips of the pincers (termed 'scraping') or dislodged and then picked out of crevices and other irregularities using the chelae and walking legs (termed 'picking'). In addition, one intertidal species, the western Atlantic Pagurus longicarpus is able to feed on detritus obtained from foam floating on the surface of the water (Seully 1978). Apart from 'scooping', many of the Otago species also 'scrape', 'scrub' or 'pick' detritus from surfaces (table 3). This may be related to the composition of the sediments on which they are found, which contain substantial quantities of pebbles and skeletal remains (Andrews 1973). The smaller species tend to be 'scrapers' and 'pickers' (e.g. Mixtopagurus sp. nov.; Pagurus sp. nov. B; Australeremus cooki; Pylopagurus stewarti: Pylopagurus sp. nov.) while the larger species tend to be 'scrubbers' (e.g. 'Pagurus rubricatus and ' $P$ '. spinulimanus; Pagurid 'smooth apricot'; Parapagurus dimorphus).

It is easy to speculate how the more specialized techniques of suspension-feeding, browsing and predation may have evolved from the basic deposit-feeding mechanisms. All hermit crabs have their body surface more or less covered with setae and 
Table 3. Summary of the feeding mechanisms of the 15 species of hermit crabs studied. Feeding types are named according to Newell (1979). $1^{\circ}$, indicates primary feeding mechanisms and $2^{\circ}$, subsidiary mechanisms. Deposit-feeding mechanisms have been subdivided as follows: SC, scooping; SB, scrubbing; SR, scraping; P, picking; G, grooming (see text for details). The structures used to filter off suspended particles have been indicated as follows: ant, antennae; antl, antennules; g», general setation; per, pereiopods. Predatory mechanisms have been subdivided into ambushing (amb) and searching (ser) techniques as defined by Hughes (1980).

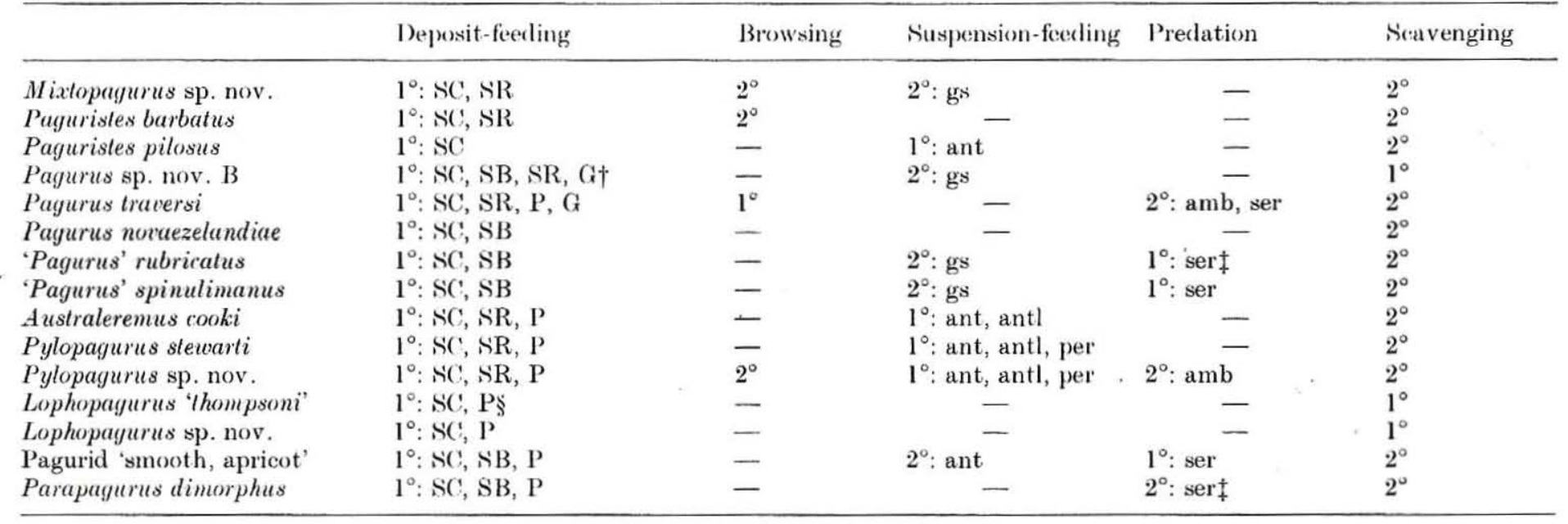

†Scrapes detritus from own shell using antennae.

$¥$ Digs pits in search of prey.

$\$$ Feeds on subsurface sediment. 
grooming the appendages is an important activity (see Roberts 1968, Kunze and Anderson 1979 and Schembri 1982, for descriptions of grooming behaviour in hermit crabs). When foraging on the substratum, sediment and other particles inevitably become trapped in the body setae and are then ingested when the crabs preen. It is likely that most hermit crabs obtain some edible material more or less accidentally in this way. In some species, the appendages are densely covered with long setae which collect substantial amounts of detritus from the surroundings (e.g. Payurus cuanensis and Anapagurus chiroacanthus, Samuelson 1970) and in at least two Otago species (Pagurus sp. nov. B and $P$. traversi) 'grooming' provides a significant proportion of the food of the crabs.

The strong currents generated by the mouthparts, and the general foraging activities of the crabs, cause considerable stirring of the surface sediment and particles resuspended thus may also be trapped by the body setae. In some species passive suspension-feeding using the general setation of the body has become a subsidiary feeding mechanism (e.g. Mixtopagurus sp. nov., Pagurus sp. nov. B. 'Pagurus' rubricatus and ' $P$ '. spinulimanus, this account; Pagurus bernhardus, Gerlach et al. 1976: Paguristes squamosus, Kunze and Anderson 1979). In other hermit crabs suspension-feeding has become an active rather than a passive process and involves both morphological and behavioural adaptations. The former include modification of some appendages into filtering structures. These are usually the antennae (e.g. Paguristes pilosus and Australeremus cooki, this account; Paguristes setosus, Greenwood 1972; Diogenes brevirostris, Boltt 1961; Paguritta harmsi, ichuhmacher 1977: Isocheles wurdemanni, Caine 1978; Payuristes hummi, Hazlett 1981) but other appendages such as the antennules, chelipeds and walking legs may also be used (e.g. Pylopayurus stewarti, P. sp. nov. and Australeremus cooki, this account: Calcinus verrilli, Markham 1977; Discorsopagurus schmitti, Caine 1980). Behavioural adaptations include sweeping the filtering appendages through the water or generating filtering currents, and orientating to face into water currents.

Increased reliance on suspension-feeding appears to be correlated with decreased mobility in a number of hermit crabs. Thus most of the species mentioned above live in attached polychaete or vermetid gastropod tubes or within coral colonies (Markham 1977, Sichuhmacher 1977, Caine 1980, Patton and Robertson 1980). The same may be true for some Otago species. In those individuals of Pylopagurus stewarti, $P$. sp. nov., and Australeremus cooki which live in bryozoan tubes, as the bryozoan colony grows larger and heavier, the crabs become increasingly less mobile and more dependent on suspension-feeding for their food. In the case of Paguristes pilosus, the suspension-feeding habit is probably correlated with the relatively detritus-poor sediments on which this species occurs.

Hermit crabs which scrape or pick at surfaces feed on both detritus and epifauna and flora collected in this way rather indiscriminately. In some cases, therefore, the division between deposit-feeding and browsing is rather tenuous. A few species however actively feed on attached algae, both unicellular and multicellular and on a variety of sedentary colonial invertebrates (e.g. Mixtopagurus sp. nov., Paguristes barbatus; Pagurus traversi, Pylopagurus sp. nov. this account; Diogenes brevirostris, Boltt 1961; Clibanarius taeniatus, Kunze and Anderson 1979). Mixtopagurus sp. nov . and Pylopagurus sp. nov. show behavioural adaptations for feeding in this manner since both species expose bryozoan zooids by chipping away at their tests with the chelae (this account). McLaughlin and Bailey-Brock (1975) report that Trizopagurus hawaiiensis fed on attached serpulid worms which the crabs picked from their tubes 
with the chelae. Clearly whether such behaviour is described as grazing or predation depends upon how these terms are defined.

True predation may have evolved from more or less casual feeding on small organisms which the crabs disturb while foraging as in Pagurus traversi and Pylopagurus sp. nov. (this account), Pagurus longicarpus (Roberts 1968) and Clibanarius virescens (Kunz and Anderson 1979). Some species have become adapted as active predators (e.g. 'Pagurus' rubricatus, ' $P$ '. spinulimanus, Pagurid 'smooth apricot', Parapagurus dimorphus, this account; Petrochirus diogenes, Caine 1975: Dardanus setifer, Kunze and Anderson 1979). Morphological adaptations for this include large size, chelae moditied as cutting and crushing devices and mouthparts armed with strong teeth and abrading setae (Caine 1975, Kunze and Anderson 1979. Schembri 1982). The most obvious behavioural adaptations are the various searching techniques exhibited by these species.

Given the omnivorous and detrivorous feeding habits of hermit crabs, it is hardly surprising that the majority of species will also feed on carrion and on moribund organisms. Scavenging behaviour is variously developed in the different species. Thus while some hermit crabs readily take all sorts of carrion, others will only reluctantly feed on it and in some cases only if starved (e.g. Payuristes pilosus. Australeremus cooki, this account; Payuristes setosus, Greenwood 1972; Paguru.: pollicaris, Roberts 1968, ('aine 1975).

There does not seem to be any obvious correlation between the taxonomic position of a species and the feeding mechanisms it employs. This may imply that the different species have evolved similar feeding mechanisms independently of each other as also postulated by Kunze and Anderson (1979).

In general, hermit crabs are mobile animals and range over relatively large areas of bottom as they forage for food. In most cases this will bring them into contact with a variety of substratum types and hence, different food sources. This is certainly the case for the majority of the ()tago species, especially those which live on the mid-and outer shelf gravels where the bottom is very heterogeneous. The ability to deal with a multiplicity of substratum types and feed on a variety of foods is clearly of adaptive value. The wide repertoire of feeding techniques shown by most species allows the crabs to exploit whatever microhabitat they happen to be in at the time. This flexibility in feeding behaviour is probably a key factor in the success of hermit crabs as a group.

\section{Summary}

The feeding behaviour of 15 species of hermit crabs from four families (Pylochelidae, Diogenidae, Paguridae and Parapaguridae) and from habitats ranging from rocky intertidal through continental shelf gravelly sediments to finer sediments on the shelf edge and continental slope, is described.

Feeding mechanisms found include various methods of deposit-feeding, browsing, suspension-feeding, predation and scavenging. Each species employs one or two primary feeding mechanisms but also a number of secondary mechanisms. Depositfeeding techniques include scooping up detritus-rich sediment, scrubbing detritus from the surface of small granules, scraping it from larger surfaces, picking it out of crevices and other irregularities, and brushing out and ingesting material which adheres to the general body setation. A few species browse on algae and sedentary colonial invertebrates which they slice or pluck off with the chelae. A number of species filter particles out of suspension using either the general setation of the body 
and/or specially modified appendages which are swept through the water. Predators either capture and ingest small organisms they encounter more or less accidentally, or actively search for prey. The latter include two species which excavate pits in the sediment in search of burrowing invertebrates. All the species studied fed upon carrion although some fed much less readily than others.

Feeding behaviour in the species studied is discussed in relation to their morphology and habitat. Previously published work on feeding in hermit erabs is reviewed. It is concluded that the broad range of feeding techniques shown by most species is probably of adaptive significance as it enables the crabs to deal with a variety of different foods and substratum types.

\section{Acknowledgments}

I am indebted to Associate Professor J. B. Jillett for providing the necessary facilities, for his interest and for many useful discussions. I am grateful to Dr. B. G. Williams and Dr. C. L. McLay for critically reading the manuscript and to the last named also for supplying me with information about the taxonomy of the New Zealand hermit crabs.

I thank the students and staff of the Portobello Marine Laboratory for assistance with many aspects of this work and particularly Mr. W. L. Tubman and Mr. C.S. Heseltine of the R. V. 'Yunida' for collecting subtidal hermit crabs and Miss B. Dickson for help in collecting intertidal species. I thank also Mr D. J. Sanderson for expert photographic assistance, Miss P. L. Cook (British Museum (Natural History)) for information on the association between hermit crabs and bryozoans and Mrs F. M. Wood for typing the manuscript.

The work described in this paper was carried out during the tenure of a University of Otago Postdoctoral Fellowship and was supported by two University

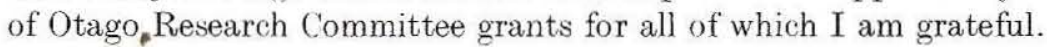

\section{References}

Alcock, A., 1905, Catalogue of the Indian decapod Crustacea in the collection of the Indian Museum. Part II. Fase. 1, Payurides. Trustees of the Indian Museum, Calcutta, $\mathrm{xi}+197 \mathrm{pp}$.

Andrews, P. B., 1973, Late Quaternary continental shelf sediments off Otago Peninsula, New Zealand. New Zealand Journal of Geology and Geophysics, 16, 793-830.

Ватнам, E. J., 1970, On behaviour of a symmetrical hermit crab. Mixtopagurus sp. nov. (Decapoda, Paguridae). ('rustaceana, 19, 45-48.

Boltт, R. E., 1961, Antennary feeding of the hermit crab Diogenes brevirostris Stimpson. Nature, 192, 1099-1100.

CaIne, E. A., 1975, Feeding and masticatory structures of selected Anomura (Crustacea). Journal of Experimental Marine Biology and Ecology, 18, 277-301.

— 1978, Habitat adaptations of Isocheles wridemanni Stimpson (Crustacea: Anomura: Diogenidae) and seasonality of occurrences in northwestern Florida. Texas University at Austin, Marine Science Institute, Contributions in Marine Science, 21, 117-123.

1980, Adaptations of a species of hermit crab (Decapoda, Paguridea) inhabiting sessile worm tubes. Crustaceana, 38, 306-310.

Cook, P. L., 1964, Polyzoa from West Africa. Notes on the genera Hippoporina Neviani, Hippoporella Canu, Cleidochasma Harmer and Hippoporidra Canu and Bassler (Cheilostomata, Ascophora). Bulletin of the British Museum of Natural History (Zoology), 12 (1), 1-35.

- 1968, Observations on living Bryozoa. Atti della Societa Italiana di Scienza Naturale e del Museo Civico di Storia Naturale di Milano, 108, 155-160. 
FAcTor, J. R., 1978, Morphology of the mouthparts of larval lobsters, Homarus americanus (Decapoda: Nephropidae), with special emphasis on their setae. Biological Bulletin of the Marine Biological Laboratory, Woods Hole, 154, 383-408.

Gerlac' , S. A., Eкstr $\phi$ м, D. K., and EckardT, P. B., 1976, Filter feeding in the hermit crab, Pagurus bernhardus. Oecologia, 24, 257-264.

Grordan, J., 1956, A bibliography of pagurid crabs, exclusive of Alcock, 1905. Bulletin of the American Museum of Natural History, 108, 253-352.

Greenwood, J. G., 1972, The mouthparts and feeding behaviour of two species of hermit crabs. Journal of Natural History, 6, 325-337.

HAZLETT, B. A., 1981, The behavioural ecology of hermit crabs. Annual Review of Ecology and Systematics, 12, 1-22.

HociHes, R. N., 1980, Optimal foraging theory in the marine context. Oceanography and Marine Biology Annual Review, 18, 423-481.

HVidex, F. II., and For EST, J., 1980. An in silu hermit crab from the early Miocene of southern New Zealand. Palaeontolof!y. 23, $471-474$.

JAc'kson, H. G., 1913, Eupayurus. Liverpool Marine Biology Committee, Memoirs on Typical British Marine Plants and Animals, 21, viii $+79 \mathrm{pp}$.+Plates I-VI.

K 'NZE, J., and ANDERson, D. T., 1979, Functional morphology of the mouthparts and gastric mill in the hermit crabs (libanarius taeniatus (Milne Edwards), Clibanarius virescens (Krauss), Paguristes squamosus MeCulloch and Dardanus setifer (Milne Edwards) (Anomura: Paguridae). Australian Journal of Marine and Freshwater Research, 30, 683-i22.

Маккна., J. C., 1977, Preliminary note on the ecology of Calcinus verrilli, an endemic Bermuda hermit crab occupying attarched vermetid shells. Journal of Zoology, London, $181,131-136$.

MCDoL' 'A AL. J. C., 1973. Modified equipment for sediment collection and rock sampling. New Zealand Oreanoyraphir Institute Resords, 1, 167-170.

MCLAl':HIIN, P. A., 1981, Revision of Pylopayurus and Tomoputgurus (Crustacea: Decapoda: Paguridae), with the descriptions of new genera and species. Part 1. Ten new genera of the Paguridae and a redescription of Tomopagjurus A. Milne Edwards and Bouvier. Bulletin of Marine Science, 31, 1-30.

McLlil'ihlin, P. A., and BaILEY-Bro''K, J. H., 1975. A new Hawaiian hermit crab of the genus Trizopayurus (Crustacea, Decapoda, Diogenidae), with notes on its behaviour. Párific Science, 29, 259-266.

Morton, J.. and Milier, M., 1968. The New Zealand sea shore. Collins, London and Auckland, $638 \mathrm{pp}$.

Newelt, R. C., 1979, Biology of intertidal animals. Marine Ecological Surveys Ltd, Kent, $\mathrm{xii}+781 \mathrm{pp}$.

OrTon, J. H., 1927, On the mode of feeding of the hermit crab Eupayurus bernhardus and some other Decapoda. Journal of the Marine Biological Association of the United Kingdom, 14, $909-921$.

Pattox, W. K., and Robertson, D. R., 1980, Pair formation in a coral inhabiting hermit crab. Oerologia, 47, 267-269.

Probert, P. K., Batha.M. E. J.. and Wilson, J. B., 1979, Epibenthic macrofauna off southeastern New Zealand and mid-shelf bryozoan dominance. New Zealand Journal of Marine and Freshwater Research, 13, 379-392.

RAIN ER, S. F., 1981, Soft-bottom benthic communities in Otago Harbour and Blueskin Bay, New Zealand. New Zealand Oreanographic Institute Memoirs, 80, 1-38.

Ronerts, M. H., 1968, Functional morphology of mouth parts of the hermit crabs, Pagurus longicarpus and Payrurus pollicaris. Chesapeake Srience, 9, 9-20.

Samielson, T. J., 1970, The biology of six species of Anomura (Crustacea: Decapoda) from Raunefjorden, western Norway. Sarsia, 45, 25-52.

S'HEMRR1, P.J., 1982. Functional morphology of the mouthparts and associated structures of Pagfurus rubricatus (('rustacea: Decapoda: Anomura) with special reference to feeding and grooming. Zoxumorpholoy!y (in the press).

S'HIHAACHER, H., 1977 , A hermit crab, sessile on corals, exclusively feeds by feathered antennae. Oecologia. 27, 371-374.

SU'LLY, E. P., 1978, Utilization of surface foam as a food source by the hermit crab, Pagurus longicarpus Say, 1817. Marine Behaviour and Physiology, 5, 159-162. 
SNow, P.J., 1973, The antennular activities of the hermit crab, Pagurus alaskensis (Benedict). Journal of Experimental Biology, 58, 745-765.

TAYLOR, P. D., and Cook, P. L., 1981, Hippoporidra edax (Busk 1859) and a revision of some fossil and living Hippoporidra (Bryozoa). Bulletin of the British Museum of Natural History (Geology), 35, 243-251.

Thompson- M. T. 1904, The metamorphosis of the hermit crab. Proceedings of the Boston Society of Natural History, 31, 147-209.

YoNGE, C. M., 1956, Marine bottom substrata and their fauna. Proceedings of the XIVIh International Congress of Zoology, Copenhagen, 1953. 